\title{
Justicia semiótica. Violencia, contrasemiosis de la imagen y producción social de lo público en la lucha por justicia y memoria de los estudiantes de Ayotzinapa, México*
}

Fecha de entrega: 30 de octubre de 2018

Fecha de evaluación: 13 de diciembre de 2018

Fecha de aprobación: 29 de enero de 2019

Mateo Martínez Abarca**

\section{Resumen}

El presente ensayo propone una lectura de la lucha por la memoria de los 43 estudiantes desaparecidos de la Escuela Normal Rural "Raúl Isidro Burgos” en Ayotzinapa, estado de Guerrero (México), desde la perspectiva de la disputa sobre la representación de la violencia. En una primera parte se intentará reflexionar sobre la violencia de Estado y las masacres actuales en México como materializaciones de la necropolítica (Mbembe, 2011, p. 35), entendida como instrumento consustancial a

* El artículo refiere a los recientes intereses investigativos del autor sobre diferentes aspectos sociales y políticos en América Latina, que incluyen temas como violencia, medio ambiente o comunidades indigenas y que lo han llevado a pertenecer a diversos grupos de estudios sociales y a adentrarse en problemáticas alusivas al desarrollo del discurso moderno. Citar como Martínez Abarca, M. (2019). Justicia semiótica. Violencia, contrasemiosis de la imagen y producción social de lo público en la lucha por justicia y memoria de los estudiantes de Ayotzinapa, México. Cuadernos de Filosofía Latinoamericana, 40(120), 187-202. DOI: 10.15332/25005375/5384

* Filósofo, escritor y analista político ecuatoriano. Ha trabajado cerca de varios movimientos populares en Ecuador y México. Es candidato a doctor en Filosofía de la Universidad Nacional Autónoma de México, investigador del Centro de Estudios Sociales de la Universidad de Coimbra (Portugal) y asesor del rectorado de la Universidad Nacional de Educación (Ecuador). 
un proyecto de acumulación capitalista de tipo neoliberal, que ha sido definido como capitalismo gore (Valencia, 2010, p. 189). En segundo lugar, se reflexionará sobre el problema de la imagen como mercancía en el contexto de la producción espectacular de una cultura del miedo. Finalmente se intentará reflexionar sobre una posible contrasemiosis que libere la imagen, para favorecer la producción social de una experiencia de lo público en el horizonte de lucha por la justicia para las víctimas.

Palabras clave: transformación social, narcotráfico, necropolítica, signo, movilizaciones.

Semiotic justice. Violence, counter-semiosis of the image and social production of the public in the fight for justice and memory of the students of Ayotzinapa, Mexico

\section{Abstract}

The following essay proposes an interpretation on the struggle for the memory of the 43 disappeared students of the Normal Rural School "Raúl Isidro Burgos" in Ayotzinapa, in the state of Guerrero, Mexico, from the perspective of the dispute on the representation of violence. In the first part, this essay tries to reflect on state violence and the current massacres in Mexico, as materializations of Necropolitics (Mbembe, 2011), understood as consubstantial instruments in a capitalist accumulation project of neoliberal type, which has been defined as Gore Capitalism (Valencia, 2010). Secondly, it will reflect on the problem of the image as a commodity, in the context of the production of spectacle as a culture of fear. Finally, this article will try to reflect on the possibility of a counter-semiosis that liberates the image as a form of social production of a public experience, in the horizon of the fight for justice for the victims.

Keywords: Social transformation, drug trafficking, necropolitics, sign, mobilizations. 


\section{Introducción}

Son muchos. Vienen a pie, vienen riendo. Bajaron por Melchor Ocampo, la Reforma, Juárez, Cinco de Mayo, muchachos y muchachas estudiantes que van del brazo en la manifestación con la misma alegría con que hace apenas unos días iban a la feria.

Así inicia la escritora mexicana Elena Poniatowska su libro La noche de Tlatelolco, memoria de la insurrección estudiantil aplastada a sangre y fuego en la plaza de las Tres Culturas el 2 de octubre de 1968. Cuarenta y seis años más tarde, en 2014, las mismas calles eran tomadas de nuevo por jóvenes estudiantes indignados con la situación cercana a un estado de guerra y barbarie en que se encuentra actualmente México tras sucesivas décadas de mal gobierno.

El Partido Revolucionario Institucional (PRI), que gobernó el país como partido de Estado entre 1929 y 2000, regresó al poder en 2012 tras un breve "interregno" de doce años de gobierno del conservador Partido Acción Nacional (PAN, de profundos vínculos con la Iglesia católica). La historia del PRI no puede disociarse de la práctica corrupta de la política en todos sus niveles, el fraude electoral y la represión violenta, a pesar de que el Estado mexicano sostuvo una fachada de "democracia formal" a lo largo de gran parte del siglo xx, que en no pocas ocasiones fue calificada como "la dictadura perfecta”.

Solo durante los dos últimos periodos de gobierno del PAN y el PRI la guerra bajo la excusa del combate al narcotráfico ha causado casi cien mil muertos. Guerra que tiene como trasfondo otra de tipo económico contra la mayoría de la población, agudizada desde que el presidente Carlos Salinas de Gortari (del PRI) pusiera en práctica durante la década de los noventa las medidas de ajuste estructural neoliberal propuestas por el Consenso de Washington. En México no ha sido posible cambiar la correlación de fuerzas desde el campo popular, a pesar de la gran capacidad de resistencia de los sectores sociales organizados, sindicatos, estudiantes, el zapatismo y los partidos de izquierda.

Existen varias hipótesis que muestran la correlación entre la ampliación de la acumulación capitalista y la violencia. Un ejemplo claro es la firma del Tratado de Libre Comercio de América del Norte (Nafta, por sus siglas en inglés) en 1992, 
que produjo la desestructuración económica del campo y de varios sectores de la industria mexicana. Como muestra un estudio de la Facultad de Economía de la Universidad Nacional Autónoma de México, el 72 \% de los productores del campo está en quiebra tras dieciocho años de libre comercio (Lozano et al., 2012, p. 155), lo cual ha provocado migración a zonas urbanas, desempleo y, en consecuencia, engrosamiento de las filas de grupos criminales y narcotraficantes. Pero el deterioro de la situación política, económica y social actual no tiene que ver solamente con una "guerra de baja intensidad" contra el tráfico de drogas o la delincuencia, sino con el despliegue de formas de violencia institucionales y no institucionales que se articulan como variables dependientes del avance de un modelo de acumulación de tipo propiamente neoliberal.

La herencia de la Revolución mexicana (1910-1920), proceso social y político profundamente inspirado en ideas socialistas, anarquistas y liberales, ha ralentizado en alguna medida el avance del neoliberalismo. Aún son visibles sus huellas y permanece vigente la memoria de sus conquistas sociales, como la consigna de Tierra y Libertad. El PRI, que en un inicio se presentó como la compleja materialización institucional y política de los principios de la Revolución, derivó aceleradamente en una poderosa maquinaria corrupta y autoritaria que ejerció hasta hace poco el poder en México como partido de Estado. La situación no cambió demasiado en los años posteriores a la hegemonía del PRI pues el gobierno mexicano siguió encabezado por un presidente construido a imagen y semejanza de los grupos económicos dominantes, impuesto en alianza con grupos que conservaron el monopolio de los medios de comunicación y se encargaron de la permanente reproducción de un consenso mediante el reemplazo de la esfera pública por una cultura de consumo despolitizada (Chomsky, 2002, p. 18).

El movimiento estudiantil mexicano tiene una larga historia de confrontación con este establishment político, que se remonta a las protestas estudiantiles y la posterior masacre de Tlatelolco en 1968 y continúa con la de 1971 - conocida como la masacre de "El Halconazo" - o más recientemente, con la huelga estudiantil de la UNAM entre 1999 y 2000. En la actualidad el movimiento estudiantil tiene una composición diversa en cuanto a lo político y social, aunque la mayoría de sus integrantes coincide en la oposición radical al PRI y al ejercicio del poder en connivencia con grandes grupos económicos y mediáticos, definido como una "imposición antidemocrática". Desde una perspectiva histórica las escuelas de formación de normalistas (profesores 
rurales) han tenido enorme importancia dentro de los movimientos sociales mexicanos como espacios para la formación de activistas y maestros comprometidos con la transformación social.

El 26 de septiembre de 2014, a pocos días de la conmemoración de la masacre del 2 de octubre de 1968, estudiantes de la Escuela Normal Rural "Raúl Isidro Burgos" se encontraban preparando su viaje para participar en la marcha conmemorativa y de protesta. Julio César Mondragón, de 22 años, era uno de ellos. Siendo de origen campesino salió junto con sus compañeros a la ciudad de Iguala para recolectar dinero y poder asistir a la marcha en Ciudad de México. Sus compañeros y él fueron atacados por policías municipales y federales y se desató una balacera. En la mañana del 27 aparece una fotografía de su cuerpo sin rostro, desollado y sin ojos, que fue difundida por las redes sociales. Julio César había sido torturado y ejecutado extrajudicialmente. Posteriormente se conoce que cuarenta y tres de sus compañeros se encontraban desaparecidos sin que hasta el día de hoy se sepa su paradero. Estudiantes, familiares y movimientos sociales mexicanos declararon públicamente que la responsabilidad es del Estado.

\section{Necropolítica y capitalismo gore}

Casi un siglo después de que Max Weber teorizara sobre el Estado como estructura institucional que concentra el monopolio legítimo de la violencia ${ }^{1}$, los primeros años del siglo xx r revelan que las dinámicas de organización de la violencia parecen haberse dispersado. Como sostiene Achille Mbembe en su ensayo Necropolítica, no se trata ya de un ejercicio de soberanía en que el reconocimiento del derecho exclusivo de ejercer la violencia dentro de un territorio es trasladado de la sociedad al Estado. Se trata de una dinámica difusa de la violencia que no siempre es exclusivamente estatal, pero que se inserta como elemento crucial dentro del marco general de una economía de la muerte. En términos de las relaciones de producción y reproducción, así como de ejercicio del poder sobre la población a través de lo que Foucault denominaba biopolítica, Mbembe sostiene que, a diferencia de la época colonial, la necropolítica actual

1 "Estado es aquella comunidad humana que, dentro de un determinado territorio (el "territorio" es elemento distintivo), reclama (con éxito) para si el monopolio de la violencia física legítima. Lo específico de nuestro tiempo es que a todas las demás asociaciones e individuos solo se les concede el derecho a la violencia física en la medida en que el Estado lo permite. El Estado es la única fuente del 'derecho' a la violencia" (Weber, 2009, pp. 83-84). 
tiene como característica principal el hecho de que la violencia no es solamente un medio, sino un fin en sí mismo.

En este sentido, el necropoder presente en los regímenes actuales de la modernidad tardía se instaura como facultad de decidir sobre la vida y la muerte de la población, en un proceso en el que los cuerpos se reifican y la propia vida humana (no solamente en cuanto fuerza de trabajo) se convierte en mercancía. La vida entonces puede ser no solamente sometida, sino también silenciada, desechada como elemento prescindible en la dinámica general tanática de acumulación capitalista. En una militarización de la vida cotidiana la masacre aparece como instrumento de control, gestión y aniquilación de poblaciones, de modo que deja de ser una excepción. Pasa de ser un "momento de irracionalidad" o "exceso" a convertirse en una norma de comportamiento habitual en función de la eficacia sistémica. Podría decirse que se trata de la generalización de la aplicación del exterminio típicamente colonial, o la idea de la "solución final" de los nazis, que pasa a erigirse en método naturalizado y cotidiano integrado al sistema político y económico mundial. Las poblaciones que representan un obstáculo ante la voluntad expansiva de dominio sobre territorios, recursos y trabajo son deshumanizadas y se convierten en objetivos de guerra no declarados, que pueden ser exterminados indiferenciadamente. Sobre esto Achille Mbembe nos dice:

En el caso de las masacres, los cuerpos sin vida son rápidamente reducidos al estatus de simples esqueletos. Desde ese momento, su morfología se inscribe en el registro de una generalidad indiferenciada: simples reliquias de un duelo perpetuo, corporalidades vacías, desprovistas de sentido, formas extrañas sumergidas en el estupor. (Mbembe, 2011, p. 64)

Siguiendo esta reflexión podría admitirse que la necropolítica, que incluye la masacre como práctica habitual, elabora también un discurso sobre la producción de una semiosis a partir de la violencia, destinada a establecer un régimen de verdad a través del terror, que contribuye así en la tarea de sometimiento de la población. En este sentido, las imágenes de crueldad que se vuelven comunes en los noticieros estelares muestran el vínculo existente entre la violencia y su búsqueda de representación. Pero detrás de la posible representación no aparece la revelación de ninguna otra realidad excepto la propia violencia en sí misma, lo que invisibiliza a la vez las historias de los cuerpos sobre los cuales se ejerce. Para Jean-Luc Nancy "la violencia en su sinsentido" es la descripción que define, en su carácter problemático, 
no solamente "el habitus sino el propio ethos del mundo actual, uno que no tiene otro mundo atrás ni sobre él":

La violencia no participa de ningún orden de razones ni en ningún conjunto de fuerzas orientadas a resultados. No es completamente intencional y excede cualquier preocupación sobre los resultados. Desnaturaliza, destroza y masacra aquello que asalta. La violencia no transforma aquello que asalta, sino que le roba su forma y significado. Lo convierte no en otra cosa que en un signo de su propia rabia, un ser o cosa ultrajado y violado: un ser o cosa cuya misma esencia consiste ahora en haber sido ultrajado y violado. (2005, p. 16)

En su ensayo Capitalismo gore (2010) la filósofa transfeminista mexicana Sayak Valencia retoma el concepto de necropolítica de Mbembe y lo sitúa en un contexto geopolítico diferente al africano, en el espacio de la frontera entre México y Estados Unidos. Desde un punto de vista histórico dicha frontera ha sido siempre escenario de complejas configuraciones: territorio ocupado por el Ejército norteamericano entre 1846 y 1848 en un conflicto tras el cual México perdió la mitad de su territorio; teatro de operaciones del Ejército revolucionario de Pancho Villa, que incursionó en Estados Unidos y atacó la población de Columbus, en Nuevo México; tierra ancestral de cinco grupos indígenas que habitan a ambos lados de la línea; asentamiento de polos industriales y explotación laboral en las maquiladoras. Y más recientemente, espacio de flujos migratorios desde toda América Latina hacia el norte, así como de disputa y control en la guerra entre carteles (con intervención de los Estados correspondientes) por el contrabando de drogas.

Valencia está de acuerdo con Mbembe en que la muerte ha pasado a ser el centro de la biopolítica, de modo que se ha transformado en necropolítica. Pero tomando como lugar de enunciación el espacio fronterizo Valencia radicaliza la noción a partir de la constatación de que el capitalismo desacraliza y mercantiliza no solamente los procesos del vivir de una población, sino también los del morir. Dicho de otra manera, el necropoder representa la gestión del último y más radical proceso de la vida: la muerte. Para Valencia la necropolítica de Mbembe vuelve a situar el cuerpo en el centro de la acción, pero en el caso de las prácticas de los sujetos fronterizos encuentra su horizonte en una representación distópica de sujetos disidentes en los que encarna lo ingobernable en cuanto a la resistencia al Estado. Paralelamente, esos sujetos están determinados por las lógicas estructurantes de los medios de comunicación, 
la violencia extrema y el neoliberalismo. Valencia sostiene que esta reconfiguración de las identidades y subjetividades deviene en un sujeto "endriago" (monstruo mítico mezcla de hidra y dragón), en un México en donde no existe un solo Estado, sino varios que actúan de forma paralela.

El sujeto endriago por excelencia es el líder de la banda criminal, que no es ni héroe ni representante de una resistencia legítima ante la biopolítica del Estado, sino un empresario que aplica y sintetiza las prácticas y demandas neoliberales más aberrantes y radicales al utilizar las lógicas del consumo y el mercado para legitimarse a través de la violencia y el asesinato (Valencia, 2010, p. 146). En este marco, para explicar el funcionamiento del capitalismo gore la filósofa mexicana encuentra necesario definir nociones como necropoder, necroprácticas, necroempoderamiento y tanatofilia. Por necropoder entiende la "apropiación y aplicación de tecnologías gubernamentales de la biopolítica para la subordinación de los cuerpos y las poblaciones" con el fin de mercantilizar el proceso de dar muerte. Las necroprácticas tienen que ver con la reapropiación de los medios de eliminación de los enemigos del Estado, pero aplicados a la eliminación de los enemigos de los sujetos endriagos, lo que crea a la vez nuevas sensibilidades culturales sobre el asesinato, naturalizándolo y volviéndolo así más "aceptable" al espectacularizarlo en los medios de comunicación. Eso posibilita "la ejecución de formas de crueldad más tajantes y más espeluznantes” para su consumo como entretenimiento televisado.

En cuanto al empoderamiento Valencia señala que puede entenderse no solo como procesos que transforman situaciones de vulnerabilidad o subalternidad en posibilidades de acción y autopoder, sino también como un proceso político de necroempoderamiento que se reconfigura a partir de "prácticas distópicas (como la tortura y el asesinato) para hacerse con el poder y obtener a través de este enriquecimiento ilícito y autoafirmación perversa" (Valencia, 2010, p. 148). Finalmente, entiende tanatofilia como el gusto por la espectacularización de la muerte, la violencia explícita, la destrucción y el sadismo en la sociedad hiperconsumista actual. Todo lo anterior la lleva a afirmar que, repensando contextualmente la biopolítica ejercida desde el Estado y la necropolítica de los sujetos endriagos, aparece un paralelismo de conservación del poder mediante la violencia, que determina lo que conceptualmente puede definirse como capitalismo gore, como "Lado B" que desenmascara las consecuencias de los procesos de globalización neoliberal no solo en México y América Latina, sino también en otros territorios del Sur Global. 


\section{Políticas del miedo: la imagen como mercancía en la era de la violencia como espectáculo}

$\mathrm{Si}$, como afirma Jean-Luc Nancy, la violencia no es solamente un habitus, sino el propio ethos del mundo contemporáneo, se vuelve necesario recuperar perspectivas que nos permitan actualizar permanentemente la crítica de la modernidad capitalista. En relación con el problema de la cultura - es decir, dentro de la esfera en la cual discurren y circulan las distintas formas de representación del mundo de lo "humano"- es ineludible señalar que no puede pensarse este tiempo catastrófico sin una aproximación hacia y desde el problema de los lenguajes de la imagen. Se trata de un tiempo en el que, como señalan Adorno y Horkheimer (2009) en su ensayo sobre las industrias culturales, "la racionalidad técnica es a la vez la racionalidad del dominio mismo"; en el que la estandarización y la producción en serie de la industria se entretejen en una cultura de masas enajenante, que busca reforzar la sumisión colectiva ante el avance de los procesos de acumulación y despojo.

"El mundo entero es conducido a través del filtro de la industria cultural" (Adorno y Horkheimer, 2009, p. 171), y la experiencia del mundo del sujeto-sujetado, destilada a partir del entretenimiento, está sobredeterminada por la prolongación del espectáculo y su reproductibilidad técnica en los medios de masas. Es además una necesidad de recuperación de la subjetividad ante el carácter enajenante de la organización del trabajo bajo el capitalismo tardío. El entretenimiento es, dicen ambos filósofos, represivo de la imaginación y buscado por quien "quiere sustraerse al proceso del trabajo mecanizado para poder estar de nuevo a su altura, en condiciones de poder afrontarlo" (Adorno y Horkheimer, 2009, p. 181). Por ende, solo es posible escapar al proceso de trabajo en la fábrica o en la oficina - añaden - adaptándose a él en los momentos de ocio.

Existe un grado de goce y placer sanguinario en la contemplación de la violencia como espectáculo, que es producido y explotado por lo que podríamos aquí proponer y denominar, siguiendo a Mbembe y a Valencia, necrosemiosis. Se trata, en el fondo, de la caricaturización de la crueldad y de la muerte, como otra función más de deshumanización y despojo de sentido de la propia vida. Por esa razón, Adorno y Horkheimer analizan la supuesta inocencia de los dibujos animados, en los cuales "la cantidad de la diversión organizada se convierte en la calidad de la crueldad organizada" (Adorno y Horkheimer, 2009, p. 183), con el objetivo de “martillar en los cerebros" para 
acostumbrar al espectador a los ritmos del trabajo y la vida, con el afán de quebrantar toda resistencia ante el tipo de relaciones sociales existente y la habituación individual y colectiva a toda clase de subordinación, vejación y maltrato. De esta forma, el placer en la violencia que se hace a quien aparece representado en el espacio de la pantalla se transforma a la vez en violencia contra quien la contempla desde fuera.

Para Guy Debord, en su texto La sociedad del espectáculo, la experiencia de vida en sociedad subsumida bajo las relaciones de producción capitalistas se muestra como una "inmensa acumulación de espectáculos". El espectáculo — dice Debord- no es un conjunto de imágenes, sino un sistema de relaciones sociales en el cual las imágenes actúan como mistificación. Por eso no puede ser entendido solamente como un producto del desarrollo técnico de la capacidad de reproducir imágenes, sino además, en cuanto a su función dentro de un aparato ideológico, como "visión del mundo que se ha objetivado". Siguiendo esta idea podríamos añadir entonces que la imagen, en cuanto objetivación producida bajo un sistema de relaciones sociales (capitalistas) y consumida y decodificada en la esfera (pública) de lo espectacular, es también cristalización - siguiendo a Marx - del valor mercantil. Por tanto, la sociedad de la industria cultural del espectáculo es la sociedad de la fetichización de la imagen ${ }^{2}$. El espectáculo es, retomando a Debord, "el capital en un grado tal de acumulación que se transforma en imagen" (1995, p. 9).

Sin embargo, la imagen como mercancía no es un mero objeto, una condensación de fuerzas sociales. Contiene tensiones, fuerzas, sintagmas que hablan de configuraciones en permanente circulación. Las imágenes determinan constelaciones fragmentarias — si se nos permite utilizar el concepto de Walter Benjamin - cuya nitidez máxima se hace notar no en el centro, sino en sus extremos y límites. Como forma-mercancía, las imágenes también tienen un valor de uso (como valor aurático) al cual se adhiere parasitariamente el valor mercantil de la época de la reproductibilidad técnica indiferenciada. En su libro Los condenados de la pantalla (2014) Hito Steyerl, artista visual y

2 Es interesante que Karl Marx utilice un ejemplo sobre lo visual para demostrar el proceso fantasmagórico y enajenante de fetichización de la mercancía: "El carácter misterioso de la forma mercancía estriba, por tanto, pura y simplemente, en que proyecta ante los hombres el carácter social del trabajo de estos como si fuese un carácter material de los propios productos de su trabajo, un don natural social de estos objetos y como si, por tanto, la relación social que media entre los productores y el trabajo colectivo de la sociedad fuese una relación social establecida entre los mismos objetos, al margen de sus productores. Este quid pro quo es lo que convierte a los productos de trabajo en mercancia, en objetos físicamente metafísicos o en objetos sociales" (Marx, 2009, pp. 88-89). 
documentalista cercana al cineasta Harun Farocki, se pregunta: “ $¡ Y$ si la verdad no se encuentra ni en lo representado ni en la representación? ¿Y si la verdad se encuentra en la configuración material de la imagen?" (Steyerl, 2014, p. 54). En definitiva, lo anterior implica preguntarse: ¿Es posible desanclar la imagen y liberar sus fuerzas internas en un horizonte de sentido emancipador?

\section{Contrasemiosis y producción social de la experiencia: hacia una justicia semiótica}

Roland Barthes sostiene que los objetos no transmiten solamente informaciones sino también sistemas estructurados de signos. En cuanto elemento de consumo reproducido ilimitadamente mediante la técnica, "el objeto no se escapa ya hacia lo infinitamente subjetivo, sino hacia lo infinitamente social" (Barthes, 1985, p. 247). Los objetos suponen, además de un uso, un sentido que los desborda. Y todos los objetos producidos socialmente deben tener sentido: son siempre significantes de algo y conllevan, por tanto, un significado. En el caso de la imagen en cuanto objeto, sabemos que actualmente es entregada de modo espectacular en una escala de masas. La decodificación del sentido del objeto-imagen corresponde sobre todo a los receptores: el objeto-imagen es polisémico, siguiendo a Barthes, por lo cual se ofrece a la posibilidad de muchas lecturas de su sentido que, como hecho, es siempre un producto social y cultural "naturalizado":

Creemos encontrarnos en un mundo práctico de usos, de funciones, de domesticación total del objeto, y en realidad estamos también, por los objetos, en un mundo de sentido, de razones, de coartadas: la función hace nacer al signo, pero este signo es reconvertido en el espectáculo de una función. (Barthes, 1985, p. 255)

Cabe entonces preguntarse: ¿Cuál es la función que cumple la imagen-objeto desde un punto de vista de la esfera pública, como campo de producción y disputa de sentidos? Para Oskar Negt y Alexander Kluge (1993) la forma a través de la cual se manifiesta la esfera pública oculta la estructura social de producción y la historia del desarrollo de sus instituciones. La televisión, reproductora de imágenes y de sentidos, es la esfera pública burguesa traducida en tecnología moderna e instrumento en un proceso en el que "el modo de producción social burgués busca siempre instalarse a sí mismo 
públicamente como orden social" (Negt y Kluge, 1993, p. 54). De ello se desprende que la esfera pública tal como está planteada actualmente es la "forma organizacional de la dictadura de la burguesía" en cuanto red de "normas, legitimaciones, delimitaciones, reglas procedimentales y separación de poderes, que impide que una esfera pública de lo político, una vez establecida, tome decisiones que perturben o nulifiquen el orden de la producción burguesa" (Negt y Kluge, 1993, p. 55).

Actualmente es posible sostener que la esfera pública se construye de manera significativa y cada vez más predominante a partir de lo que Frank Furedi ha denominado políticas del miedo. Estas "capturan la sensibilidad hacia la vida en general" como fuerza que domina la imaginación pública. El miedo no nació de forma espontánea, sino que fue politizado conscientemente. A lo largo de la historia ha sido utilizado políticamente por las elites gobernantes, pero en la actualidad estas no necesitan construirlo - según Furedi- artificialmente. "Gracias al agotamiento de la política, este sentimiento está ya incrustado dentro de la sociedad” (Furedi, 2005, p. 133).

Sobre esta última afirmación de Furedi, retomando el caso actual de México y más aún el de América Latina, es necesario decir que hay que situar esta idea en contexto. Existe una producción del miedo como discurso de sentido, que busca paralizar la capacidad de reacción de la sociedad ante el avance de un modelo de acumulación y despojo neoliberal que se articula con el crimen organizado (el capitalismo gore del cual habla Sayak Valencia), en el que la violencia y la masacre han pasado a ocupar un papel central.

Ante esta violencia de la necropolitica, que incluye también - como hemos dichouna necrosemiosis, las víctimas empiezan a reaccionar mediante la organización y la movilización. A poco de conocerse la brutal tortura y ejecución de Julio César Mondragón junto a cinco estudiantes y la desaparición de otros 43 , se empezaron a organizar en todo México manifestaciones de protesta. Articuladas bajo la consigna "Vivos se los llevaron, vivos los queremos", las movilizaciones han sido catalogadas como las más intensas de las últimas décadas. Al conocerse que varias instancias del Estado participaron en la desaparición de los estudiantes, la demanda social de asignación de responsabilidades y justicia fue dirigida directamente hacia el gobierno del PRI. Entre los elementos fundamentales dentro de la plataforma de acción colectiva de las movilizaciones ha sido posible percibir un uso de la imagen como ejercicio de recuperación de la memoria de los muertos y desaparecidos, 
de gran importancia dentro de una disputa por la experiencia de sentido en el marco de lo público.

El ejercicio de la crueldad ha estado presente a lo largo de todo el desarrollo de la modernidad en América Latina. Como sostiene Jean Franco en su libro Cruel modernity (2013), lacrueldad puede entenderse como parte constitutiva de un proceso continuo propiamente moderno. Desde la Conquista, pasando por las revoluciones políticas, la represión y guerra sucia de las dictaduras contra la izquierda o los grupos insurgentes, hasta sus manifestaciones actuales extractivista o del narcotráfico - en las que los límites entre el Estado y el crimen organizado se vuelven difusos-, el uso de la crueldad ha sido recurrente. Las poblaciones que han sido vistas como "obstáculos" ante el avance de la "modernización" (política, económica o social) han sufrido los efectos de diversos tipos de deshumanización utilizados como justificación para la aplicación de una violencia sin límites sobre los cuerpos de los otros, incluso hasta el exterminio. Indígenas, campesinos, mujeres, estudiantes y trabajadores han sido las victimas usuales.

La persistencia de la crueldad no se remite solamente a México o América Latina, pero Franco llama la atención sobre la necesidad de pensar las condiciones históricas específicas bajo las cuales se convirtió en instrumento de ejércitos, gobiernos y grupos armados en el continente. Del otro lado se encuentran aquellos que resisten y se enfrentan a la violencia recuperando la memoria, para quienes restituir la humanidad al rostro arrancado y la corporalidad a la persona desaparecida constituye parte esencial de la búsqueda de justicia. Es posible pensar, entonces, que no solamente la crueldad ha sido parte constitutiva de la modernidad latinoamericana, sino también la obstinación de la memoria como producción de un discurso histórico alternativo al de los Estados y sus aparatos de propaganda. Y en una contrasemiosis como ejercicio de re-construcción del sentido en medio del sinsentido de la represión política, el horror y la crueldad.

\section{Conclusiones}

En este trabajo he tratado de pensar sobre la imagen en el contexto de la lucha específica en pos de verdad y justicia en el caso de los estudiantes asesinados y desaparecidos de la Escuela Normal Rural "Raúl Isidro Burgos", en Ayotzinapa, estado de Guerrero (México). Ante las imágenes de crueldad difundidas públicamente y luego de las intensas movilizaciones que siguen aconteciendo hasta el día de hoy, es posible 
afirmar que el rostro de Julio César Mondragón se halla en disputa en medio de la lucha colectiva por la memoria de las víctimas. La puesta en escena de la crueldad y la muerte (humillando y deshumanizando a la víctima al grado de volverla mercancía espectacular) es ejemplo de la instrumentalización de la necrosemiosis como herramienta de control social en el contexto del capitalismo gore. La violencia que reportan esta y otras imágenes se deduce de la esencia misma del proceso de reproducción capitalista, en el cual la mercantilización de la muerte cruel es una pieza en el engranaje de la acumulación y el despojo como discurso ideológico. En el fondo se trata de paralizar a la sociedad mediante el miedo proyectando la idea de que es imposible imaginar un mundo distinto al existente. La circulación de la crueldad en la cultura de masas actual implica la materialización de la necroimagen (y una necrosemiosis como producción y consumo de significaciones tanáticas).

Sin embargo, el rostro en reconstrucción de Julio César Mondragón es el rostro de la lucha por la justicia en el marco de la búsqueda de los estudiantes que aún no han sido localizados. En este caso, las víctimas han sido capaces de producir una "solidaridad que puede ser captada mediante los sentidos" (Negt y Kluge, 1993, p. 78) y que disputa y reconstruye la imagen violentada. De esta forma recuperaron la producción colectiva de un tipo distinto de experiencia de lo público, considerando que lo público es socialmente producido, pero también socialmente transformable. A manera de conclusión de este ensayo es posible proponer como aporte un nuevo concepto para comprender los procesos de lucha colectiva en los que la semiosis de la imagen cumple un papel relevante. Este concepto, que queremos llamar aquí justicia semiótica, proviene de la experiencia y las prácticas concretas de las luchas por la memoria tanto en México, como en América Latina y el Sur Global.

Se trata de un concepto que toma prestadas las ideas de una sociología de la imagen como la que propone Silvia Rivera Cusicanqui y una sociología de las ausencias, propuesta por Boaventura de Sousa Santos. Podría definirse como la descripción de una semiosis cuya politicidad se narra mediante la recodificación de sentidos a partir de los rostros ausentes y los cuerpos desaparecidos. Su propósito no es solamente ejemplificar formas de intervención en la esfera pública "burguesa", sino abrir caminos para pensar las condiciones de posibilidad de otra experiencia del mundo, a partir de la praxis creadora de la lucha colectiva por la justicia. Como afirmaba Walter Benjamin en sus Tesis sobre el concepto de historia, ni los muertos se encuentran a salvo ante la acción de un enemigo que no ha cesado de vencer. En un mural en algún lugar de 
México reza la siguiente consigna: "Me quitaron el rostro, pero hoy los que marchan son mi nueva cara". Por consiguiente, en última instancia, la justicia semiótica excede el campo de la imagen para situarse en un territorio de lucha social más amplio y complejo, cuyo horizonte es la transformación radical de este, nuestro insoportable tiempo histórico presente.

Figura 1. \#AyotzinapaSomosTodos

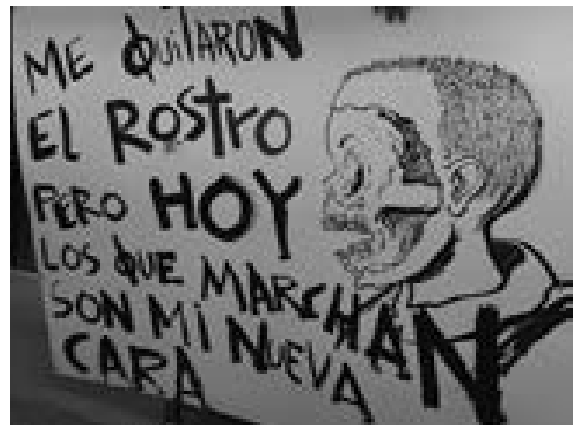

Fuente: Carrillo (2014).

\section{Referencias}

Adorno, T. y Horkheimer, M. (2009). Dialéctica de la Ilustración. Madrid: Trotta.

Barthes, R. (1985). La aventura semiológica. Buenos Aires: Paidós.

Carrillo, T. (2014). AyotzinapaSomosTodos, "Me quitaron el rostro, pero hoy los que marchan son mi nueva cara". Recuperado de https://twitter.com/taliacarrillo.

Chomsky, N. (2002). Manufacturing consent: The political economy of mass media. Nueva York: Pantheon Books.

Debord, G. (1995). La sociedad del espectáculo. Santiago de Chile: Naufragio.

Franco, J. (2013). Cruel modernity. Durham, NC: Duke University Press.

Furedi, F. (2005). The politics of fear. Londres: Continuum Books. 
Lozano, D., Lozano, L., Zavala, G., Otero, I., Lozano, J., Vázquez, J. y Moctezuma, D. (2012). Resultados de 18 años del TLCAN y 20 años de las modificaciones al artículo 27 constitucional. México: CAM, Facultad de Economía, Unam.

Marx, K. (2009). El capital. Crítica de la economía política. México: Siglo xxi.

Mbembe, A. (2011). Necropolítica, seguido de Sobre el gobierno privado indirecto. Santa Cruz de Tenerife: Melusina.

Nancy, J. L. (2005). The ground of the image. Nueva York: Fordham University Press.

Negt, O. y Kluge, A. (1993). Public sphere and experience: Toward an analysis of the bourgeois and proletarian public sphere. Minneapolis: University of Minnesota Press.

Poniatowska, E. (1971). La noche de Tlatelolco. México: Era.

Santos, B. de S. (2012). Public sphere and epistemologies of the South. Africa Development, 37(1), 43-67.

Steyerl, H. (2014). Los condenados de la pantalla. Buenos Aires: Caja Negra.

Valencia, S. (2010). Capitalismo gore. Santa Cruz de Tenerife: Melusina.

Weber, M. (2009). La política como vocación. Madrid: Alianza. 